\title{
Kelayakan Ekonomi Alat Tangkap Ikan Bandrong Cakalang di Perairan Dangkal
}

\author{
Economic Feasibility of Cakalang Bandrong (Skipjack Tuna Blanket Net) in The \\ Shallow Waters
}

\section{Andi Adam Malik ${ }^{1}$, Andi Sitti Halimah ${ }^{1 *}$}

${ }^{1}$ Fakultas Pertanian Peternakan dan Perikanan, Universitas Muhammadiyah Parepare, Jalan Jend. Ahmad Yani, KM 6, Kota Pare-Pare, Sulawesi Selatan, 91131, Indonesia

*Korespondensi: ima_gaansil@yahoo.co.id

\begin{abstract}
ABSTRAK
Perairan Kabupaten Barru Sulawesi Selatan memiliki potensi kelautan dan perikanan yang sangat besar dengan beragam alat tangkap yang digunakan. Salah satunya adalah bandrong Cakalang (Skipjack Tuna Blanket Net) yang merupakan alat tangkap hasil modifikasi masyarakat setempat dengan menggabungkan kemampuan melihat tanda-tanda alam dan kemampuan merancang alat yang dapat menangkap ikan pelagis besar di air dangkal. Penelitian ini bertujuan untuk mengetahui kelayakan aspek ekonomi bandrong Cakalang yang digunakan nelayan di di Perairan dangkal Kabupaten Barru. Pengumpulan data dilakukan melalui wawancara dengan pemilik bandrong dan nelayan, sedangkan observasi dilakukan terhadap 3-unit alat dan metode penangkapan bandrong Cakalang. Hasil penelitian memperoleh nilai NPV dan B/C ratio >1, IRR $>12 \%$ suku bunga berlaku, dengan masa pengembalian modal kurang dari 2 tahun, sehingga usaha penangkapan ikan dengan menggunakan alat tangkap bandrong Cakalang dianggap menguntungkan dan layak untuk dikembangkan.
\end{abstract}

Kata kunci: Bandrong Cakalang, Alat Tangkap, Aspek Ekonomi, Perairan Dangkal, Kelestarian Ikan

\begin{abstract}
The district waters of Barru, South Sulawesi have enormous fishery potential and taken by various fishing gears. One of the fishing gears is the Cakalang bandrong (skipjack tuna blanket net) which is a fishing gear modified by the local community, catch large pelagic fish in shallow water. This study aims to determine the economic feasibility of the skipjack tuna blanket net used by fishermen in the shallow waters Barru. Data collection was carried out through interviews with bandrong owners and fishermen, while observations were made on 3 units of Cakalang bandrong fishing gear and methods. The results showed that the NPV and B/C ratio $>1$, IRR $>12 \%$ interest rates, with a payback period of less than 2 years, so that the fishing using the skipjack tuna blanket net fishing gear is considered profitable, so it is feasible to be developed.
\end{abstract}

Keywords: Bandrong Cakalang, Fishing Gear, Economic Aspects, The Shallow Waters, Fish Sustainable.

\section{PENDAHULUAN}

Garis pantai Indonesia memiliki panjang $80.791 \mathrm{~km}$ dan merupakan kawasan dengan penduduk mayoritas bermukim di pesisir pantai, demikian halnya wilayah Kabupaten Barru (termasuk Propinsi Sulawesi Selatan) yang sebagian wilayahnya berupa wilayah pesisir sepanjang $87 \mathrm{~km}$. Basis ekonomi masyarakatnya adalah sektor perikanan laut, selain sektor pertanian di 
wilayah pedalaman. Perikanan laut yang dimaksud termasuk: (a) budidaya ikan, udang, dan rumput-laut di laut, (b) Budidaya tambak-tambak: udang, bandeng dan rumput laut; dan (c) penangkapan ikan di laut. Dengan pengembangan sektor kelautan ini maka Pemerintah Daerah setempat berusaha melakukan pengembangan wilayah dengan mengutamakan basis ekonomi rakyat di wilayah tersebut. Dalam penelitian ini, penulis focus pada pengangkapan ikan di laut, mengingat jumlah nelayan tangkap di laut wilayah Kabupaten Barru relatif lebih banyak.

lndonesia dengan perairan tropis yang kaya akan berbagai jenis ikan dengan jumlah individunya relatif sedikit, dibanding daerah yang beriklim sedang atau dingin sehingga alat tangkap ikan dan cara penangkapannya juga disesuaikan dengan sifat hidup dan daerah tempat hidup ikan yang akan ditangkap (Genisa, 1998). Berhasil tidaknya tiap usaha penangkapan ikan di laut pada dasarnya adalah berkaitan dengan usaha bagaimana mendapatkan daerah penangkapan (fishing ground), gerombolan ikan dan keadaan potensinya, untuk kemudian dilakukan operasi, termasuk alat tangkap yang digunakan (Kusdiantoro, 2019). Penggunaan racun dan bahan peledak, trawl dan penggunaan alat tangkap ikan bergerak lainnya cenderung mengeruk ke dasar laut yang berakibat pada perusakan bentos dan organisme lain. Penelitian Arisandi (2016) menyebutkan jika salah satu penyebab kerusakan biota laut adalah alat tangkap termasuk penggunaan trawl yang dapat memutus regenerasi ikan. Untuk itu, penggunaan alat tangkap ikan dalam pencapaian produksi yang baik harus meminimalkan dampak negatif bagi lingkungan dan kehidupan biota perairan (Silaban, et.al., 2017).

Perairan Kabupaten Barru terdapat jenis alat tangkap berupa Blanket Net yang dimodifikasi oleh masyarakat setempat menjadi Bandrong Cakalang. Alat ini telah lama digunakan jauh sebelum penggunaan alat tangkap modern lain. Keberadaan alat tangkap hasil modifikasi nelayan lokal diharapkan mampu mengembangkan usahanya sehingga perlu mendapatkan perhatian karena usaha yang dilakukan umumnya masih bersifat sederhana/tradisional (Tangke, 2011). Upaya meningkatkan taraf hidup atau pendapatan nelayan dapat dilihat dari produksi hasil tangkapannya, dan umumnya dilakukan dengan mengusahakan unit alat tangkap yang produktif, yakni yang tinggi dalam jumlah dan nilai hasil tangkapannya. Artinya, alat tangkap yang dimaksud harus bersifat ekonomis, efisien dan menggunakan teknologi yang sesuai dengan kondisi setempat serta tidak merusak kelestarian sumberdaya perikanan (Wisudo et al, 2002). Secara umum, konstruksi dari bandrong sangat sederhana dan tidak sulit dalam penggunaannya. Subani dan Barus (1989) menjelaskan cara menggunakan bandrong yaitu memasang jaring pada bangunan bandrong kemudian jaring diturunkan ke arah dasar perairan dengan mengulur tali untuk pengangkatan. Setelah ikan terkumpul, lalu secara perlahan tali ditarik (jaring diangkat ke arah permukaan) hingga kumpulan ikan berada di dalam jaring dan hasil tangkapan diangkat dari jaring.

Penelitian Mallawa, et.al. (2020) menyimpulkan jika ikan cakalang layak tangkap dengan menggunakan bandrong mencapai $37.84 \%$ dibanding alat penangkapan ikan cakalang skala tradisional lainnya seperti pancing tangan, pancing tonda dan rawai tegak. Disamping itu, bandrong cakalang dikategorikan sebagai alat penangkapan ikan berkelanjutan karena bandrong dinilai aman bagi habitat, aman bagi nelayan, aman bagi konsumen, aman bagi biota yang dilindungi. Meski demikian, penggunaan alat tangkap ini juga perlu mempertimbangkan aspek ekonomi yang berkaitan dengan keuntungan yang diterima oleh nelayan dengan pertimbangan modal yang dimiliki untuk aktivitas tangkapnya. Aspek ini berkaitan dengan selisih antara 
pengeluaran uang dengan pemasukan yang akan diterima oleh nelayan dengan penggunaan bandrong sebagai alat tangkap. Hal tersebut yang mendasari pelaksanaan penelitian ini, dengan tujuan menghitung keuntungan dan kelayakan usaha perikanan cakalang dengan alat tangkap bandrong di perairan dangkal Kabupaten Barru.

\section{METODE PENELITIAN}

Penelitian ini dilaksanakan di Perairan Kabupaten Barru Sulawesi Selatan dan menggunakan metode deskriptif yang bersifat studi kasus. Pengambilan sampel dilakukan dengan mengambil semua data dari 3 unit alat tangkap bandrong Cakalang yang beroperasi di lokasi penelitian. Pengambilan data dilakukan melalui wawancara dan observasi untuk mendapat data jenis dan ukuran perahu, harga dan biaya-biaya yang meliputi: investasi usaha, biaya produksi, biaya penyusutan, jenis dan berat hasil tangkapan, nilai produksi penangkapan, dan metode pengoperasian alat tangkap. Responden yang dipilih terkait dengan usaha perikanan tangkap yang menggunakan alat tangkap tersebut, seperti pemilik bandrong dan nelayan yang dipekerjakan pada masing-masing unit.

Analisis yang digunakan dalam kelayakan aspek ekonomi terdiri dari $N P V, I R R$, B/C Ratio, dan Payback Period. Analisis tersebut bertujuan untuk melihat suatu usaha penangkapan ikan yang menggunakan alat tangkap bandrong bersifat menguntungkan atau tidak serta prospek keberlanjutan usaha tersebut.

\section{NPV (Net Present Value)}

NPV merupakan perbedaan antara nilai sekarang (Present Value) dari manfat dan biaya. Nilai NPV yang positif dapat diartikan sebagai besarnya keuntungan yang diperoleh dari usaha tersebut, demikian halnya jika nilai NPV negatif menunjukkan kerugian yang diterima (Pramudya, 2014). Analisis NPV dapat diketahui dengan rumus:

Dimana:

$$
\sum_{t=1}^{n} B t-C t /(1+i)
$$

$$
\begin{aligned}
\mathrm{B} & =\text { Manfaat (Rp/tahun) } \\
\mathrm{n} & =\text { Umur Produksi } \\
\mathrm{t} & =\text { Tahun ke-t } \\
\mathrm{C} & =\text { Biaya (Rp/tahun) } \\
\mathrm{i} & =\text { Discount Rate (\%/tahun) }
\end{aligned}
$$

Dari perhitungan NPV yang diperoleh dapat diambil keputusan:

Jika NPV $\geq 0$, maka usaha layak untuk dijalankan

Jika NPV < 0, maka usaha tidak layak untuk dijalankan

\section{IRR (Internal Rate of Return)}

IRR (Internal Rate of Return) menilai besarnya pengembalian usaha terhadap investasi yang ditanamkan. Besaran yang dihasilkan dari perhitungan ini dinyatakan dalam satuan persentase $(\%)$.

$$
I R R=i^{\prime}+\frac{N P V^{\prime}}{\left(N P V^{\prime}-N P V^{\prime \prime}\right)}\left(i^{\prime \prime}-i^{\prime}\right)
$$

Dimana:

$i^{\prime} \quad=$ Tingkat suku bunga yang menghasilkan NPV positif

$i^{\prime \prime} \quad=$ Tingkat suku bunga yang menghasilkan NPV negatif

NPV' = NPV yang bernilai positif

NPV" = NPV yang bernilai negatif

\section{B/C Ratio (Benefit Cost Ratio)}

Nilai B/C Ratio dapat dinyatakan dalam rumus:

Keterangan:

$$
\text { Net B/C }=\sum_{t=1}^{n} \frac{\frac{B t}{(1-i) t}}{\frac{C t}{(1-i) t}}
$$

$$
\begin{aligned}
\mathrm{B} & =\text { Manfaat (Rp/tahun) } \\
\mathrm{N} & =\text { Umur Produksi } \\
\mathrm{t} & =\text { Tahun ke-t } \\
\mathrm{C} & =\text { Biaya }(\mathrm{Rp} / \text { tahun }) \\
\mathrm{i} & =\text { Discount Rate (\%/tahun) }
\end{aligned}
$$

Jika nilai $\mathrm{B} / \mathrm{C}>1$, maka usaha tersebut layak untuk dijalankan

Jika nilai $\mathrm{B} / \mathrm{C}<1$, maka usaha tersebut tidak layak untuk dijalankan 


\section{PP (Payback Period)}

PP merupakan metode yang digunakan untuk mengukur waktu pengembalian investasi dari suatu usaha (Pratama, 2012). PP dapat dihitung dengan rumus:

$$
\begin{aligned}
\text { PP } & =\frac{\text { Investasi }}{\text { Benefit }} \\
\text { Payback } & \text { Period dimaksudkan }
\end{aligned}
$$
untuk menghitung berapa tahun dapat diperoleh kembali nilai investasi yang telah dikeluarkan dalam bentuk pembelian atau pengadaan unit bandrong.

\section{BEP (Break Event Point)}

menganalisis hubungan antara biaya tetap, biaya variable, keuntungan, dan volume aktivitas (Muhfizar dan Hendra, 2020). BEP diketahui dari rumus:

$$
\begin{gathered}
\text { BEP Produksi }=\frac{\text { Total Biaya Produksi }}{\text { Harga Jual }} \\
\text { BEP Harga }=\frac{\text { Total Biaya Produksi }}{\text { Total Produksi }}
\end{gathered}
$$

\section{HASIL DAN PEMBAHASAN}

Secara geografi lokasi penelitian terletak di pantai barat Sulawesi Selatan yang berhadapan langsung dengan Selat Makassar, berada di kedua sisi Teluk Awerange (Utara dan Selatan), dan hampir menyerupai daerah lain yang berada di kawasan pantai yaitu berkarang dan berpasir. Teluk Awerange secara ekonomi sangat berarti bagi penduduk sekitarnya karena dimanfaatkan sebagai daerah pemukiman, budidaya tambak, persawahan, penangkapan ikan, pelabuhan rakyat Awerange dan berbagai aktifitas lainnya. Komponen alat tangkap bandrong ada 3, yaitu: 1) Alat tangkap atau jaring bandrong berbentuk empat persegi panjang dengan sayap pada tiga sisinya. Sayap tersebut berada pada sisi kiri, kanan dan bawah dari badan jaring. Alat ini mempunyai lebar 17.25meter, sedangkan panjangnya adalah 25.5 meter.
Lebar sayap kiri-kanan yaitu 8.25meter dan panjangnya 8.25meter. Sayap belakang (bawah) berukuran lebar 5.25 meter dan panjang 25.5 meter. Badan dan sayap kiri-kanan serta sayap belakang jaring terbuat dari tali nylon multifilament dengan mesh $40 \mathrm{~mm}$ pada bagian sayap bawah dan badan jaring sedangkan sayap kiri-kanan mempunyai mesh size $110 \mathrm{~mm}$.

Jaring ini dilengkapi dengan tali ris utama atas berdiameter $20 \mathrm{~mm}$ yang terbuat dari serat (tali ijuk) dan tali sekunder (passusu'na) berdiameter $5 \mathrm{~mm}$ terbuat dari jenis polyethylene. Tali ris ini melingkari badan dan sayap belakang jaring yang dijadikan sebagai tempat mengikat jaring. Pada masing-masing sudut badan jaring terdapat kili-kili (bangkung-bangkung) yang mempunyai panjang $19 \mathrm{~cm}$, lebar $9 \mathrm{~cm}$ dan tebal $4.5 \mathrm{~cm}$ dengan diameter lingkaran $5 \mathrm{~cm}$. Sayap jaring diikatkan ke tali ris badan jaring dengan jarak 2 meter dari permukaan bagian atas jaring. 2) Perahu, terbuat dari kayu jati (Tectona grandis) agar dapat tahan lama. Rancangan perahu ini disesuaikan dengan fungsinya.

Tenaga kerja berada pada salah satu sisi perahu pada saat pemasangan jaring (setting). Perahu ini berfungsi sebagai alat transportasi dari pangkalan pendaratan ke daerah penangkapan (Rumah Bandrong) dan sebaliknya. Disamping itu juga berfungsi sebagai tempat penampungan sementara hasil tangkapan sebelum diantar ke punggawa bonto (pengecer).

Perahu ini dilengkapi dengan tenaga penggerak mesin tempel (katinting) 5 pk. 3) Rumah Bandrong, diperkuat oleh 5 unit tiang, dengan perincian masing-masing terdiri atas 4 bambu perunit tiang. Tiang bambu ini dipasang salingmerangkai pada bagian ujungnya sehingga membentuk segitiga sama kaki. Kelima tiang tersebut dihubungkan dengan beberapa bambu pada pertemuan masing-masing tiang dan bagian kaki yang dipasang secara horizontal. Hal ini bertujuan untuk memperkokoh rumah bandrong. 
Pada bagian atas pertemuan rangkaian dari tiang dipasang potongan potongan bambu kecil yang dipasang sejajar dengan 5 unit tiang yang berfungsi sebagai tempat tinggal nelayan bandrong. Pada sisi kiri dan kanan terdapat bangunan yang lebih tinggi. Bagian kanan sebagai tempat punggawa yang bertugas sebagai tempat mengawasi gerak-gerik ikan dan komando operasi penangkapan. Bagian kiri berfungsi sebagai tempat sawi untuk menghadang pergerakan ikan pada saat penarikan jaring (hauling).

Persiapan awal dilakukan sebelum berangkat ke fishing ground, nelayan harus mempersiapkan perbekalan (konsumsi) masing-masing untuk tiap satu kali trip. Setelah semuanya siap, perahu kemudian berangkat ke daerah penangkapan ikan yang ditempuh selama sekitar 30 menit. Sesampai di lokasi penangkapan (rumah bandrong) mesin tempel disimpan ditempat yang telah disediakan di bagian balai-balai mesin. Punggawa dan krunya kemudian naik ke balai-balai induk. Pada tahap ini punggawa memulai proses operasi dengan membaca mantra-mantra. Kegiatan ini dilakukan setiap kali ke balai induk.

Punggawa juga sangat berperan dalam menentukan saat yang tepat untuk memulai penarikan jaring. Sambil mengamati gerak-gerik ikan, punggawa dengan sabar mengucapkan mantramantra untuk memanggil ikan. Jika telah melihat tanda-tanda kedatangan gerombolan ikan, punggawa menarik tali sayap kanan yang sekaligus sebagai tanda agar kru yang lain ikut menarik tali lain sesuai dengan posisi masing-masing. Disaat penarikan jaring semua kru juga melempari gerombolan ikan agar tidak melarikan diri ke arah rumah bandrong. Jika semua sisi jaring telah berada di atas permukaan air $(30-50 \mathrm{~cm})$ maka tali diikatkan pada bambu semula. Kalau ada ikan di dalam areal jaring maka 5 orang kemudian ke perahu untuk melakukan pemanenan. Proses pemanenan dimulai dari bagian atas sayap belakang jaring menuju ke bagian depan jaring. Bila sudah terlihat maka ikan diangkat dengan badan jaring ke perahu. Setelah semua ikan dinaikkan ke perahu maka semua tali kembali diulur ke posisi semula oleh tenaga kerja yang ada di rumah bandrong.

Keberhasilan operasi penangkapan ikan sangat tergantung pada keterampilan punggawa dalam mengoperasikan alat tangkap bandrong terutama dalam mengamati keberadaan ikan. Waktu penarikan jaring dengan jarak ikan dari sayap jaring pengintai ikan hampir sama untuk masing-masing jenis ikan. Jaring Bandrong ditarik ketika gerombolan ikan telah berada dipertengahan jaring, kecuali ikan Cakalang yang harus dilakukan penarikan jaring ketika jaraknya sekitar 15 meter dari sayap jaring pengintai ikan. Umumnya punggawa telah mengoperasikan alat di atas 40 tahun. Bandrong sangat mudah untuk dioperasikan. Tenaga kerja yang digunakan sebanyak enam orang namun dalam keadaan darurat dapat dioperasikan oleh dua atau satu orang saja.

Usaha perikanan tangkap umumnya mempunyai tingkat resiko yang lebih besar dan penuh dengan ketidakpastian sehingga sangat penting untuk membuat penaksiran secara obyektif. Penaksiran yang obyektif terhadap aspek ekonomi usaha perikanan tangkap merupakan kontribusi yang sangat penting untuk dipertimbangkan dalam perencanaan dan pengembangan suatu teknologi penangkapan ikan. Tujuan utama dari suatu kegiatan ekonomi adalah untuk memperoleh laba atau profit sebesarbesarnya, artinya jika jumlah penerimaan yang diperoleh dalam periode tertentu lebih besar daripada jumlah pengeluaran yang dilakukan dalam periode yang sama. Jika pengeluaran lebih besar dari penerimaan berarti terjadi hal sebaliknya kerugian yang diperoleh. Data hasil perhitungan kelayakan aspek ekonomi dapat dilihat pada tabel 1 . 
Tabel 1. Hasil Perhitungan Kelayakan Finansial Alat Tangkap Bandrong

\begin{tabular}{lll}
\hline Komponen & Nilai & Keterangan \\
\hline NPV & Rp2.736.316,60 & Layak \\
IRR & $21,2797 \%$ & Lebih besar dari suku bunga 12\% \\
B/C Ratio & 1.246 & Layak \\
PP & 1,98 & 1 tahun 9 bulan 8 hari \\
BEP & Rp13,494,678.3 & Per tahun untuk 3 unit alat \\
\hline
\end{tabular}

Kegiatan usaha penangkapan ikan dengan alat tangkap bandrong Cakalang di lokasi penelitian ini sebesar rata-rata Rp2,736,316.6 dengan dasar asumsi menggunakan tingkat suku bunga $12 \%$ sesuai suku bunga pinjaman dari bank. Nilai NPV adalah positif sehingga bisa dikatakan bahwa penggunaan alat tangkap bandrong Cakalang bagi nelayan setempat dapat menghasilkan keuntungan setelah melunasi biaya kegiatan penangkapan dan biaya bunga. Demikian pula dengan nilai IRR sebesar $21.2797 \%$ yang lebih besar dari suku bunga pinjaman yang berlaku saat penelitian yaitu sebesar $12 \%$ maka usaha penangkapan ikan dengan alat tangkap bandrong Cakalang dianggap layak untuk dilanjutkan di Perairan dangkal Kabupaten Barru.

Sebenarnya ditinjau dari segi kelayakan pendapatan konsep B/C Ratio mengandung kerelatifan. Semakin besar skala usaha yang berarti keuntungan nominal lebih besar, maka meskipun B/C Ratio kecil tidak menjadi soal karena pendapatan secara nominal lebih besar sehingga mencukupi kebutuhan hidup minimal. Berbeda dengan usaha dengan investasi kecil, walaupun analisis memberikan nilai B/C Ratio besar namun pendapatan secara nominal kecil, sehingga ada kalanya pendapatan hanya terbatas pada margin standar terendah dari nelayan. Nilai B/C Ratio dari kegiatan penangkapan dengan menggunakan alat tangkap bandrong yaitu 1.246. Hal ini berarti bahwa semua pengeluaran atau biaya total akan tertutupi oleh pendapatan dan masih tersisa keuntungan sebesar 24,6\% yang dihasilkan dalam kegiatan nelayan tersebut. Dengan nilai B/C Ratio lebih besar dari satu maka kegiatan penangkapan dengan bandrong Cakalang di lokasi penelitian ini layak untuk dilanjutkan.

Hasil analisis Payback Period (PP) dalam penelitian ini adalah 1.98, artinya usaha penangkapan ikan Cakalang dengan menggunakan alat tangkap bandrong di Perairan Kabupaten Barru dapat mengembalikan modal pengeluaran kurang dari 2 tahun. Wiratama, et.al (2017) menjelaskan jika suatu kegiatan usaha dengan waktu pengembalian modal (Payback Period) yang sesuai, dapat dipilih untuk dijadikan kegiatan usaha. Adapun nilai BEP berorientasi pada seberapa banyak jumlah tangkapan yang harus diperoleh agar kegiatan nelayan impas. Nilai BEP dari alat tangkap bandrong Cakalang yaitu Rp13.494.678,3 per tahun. Ini berarti titik impas dari kegiatan nelayan menggunakan bandrong sebesar Rp13.494.678,3 per tahun dan akan memberikan keuntungan jika jumlah yang diterima dari hasil tangkapan bernilai lebih besar dari nilai tersebut. Karena total tangkapan mencapai Rp22.047.000 per tahun maka kegiatan penangkapan ikan oleh nelayan menggunakan bandrong di Perairan dangkal Kabupaten Barru dapat dikatakan menguntungkan.

\section{KESIMPULAN}

Hasil penelitian menyimpulkan bahwa dengan mempertimbangkan hasil perhitungan aspek ekonomi yang telah dianalisis maka usaha kegiatan penangkapan ikan dengan alat tangkap bandrong Cakalang secara ekonomi menguntungkan bagi masyarakat nelayan di sekitar Perairan Kabupaten Barru. 


\section{DAFTAR PUSTAKA}

Arisandi. (2016). Inkonsistensi Kebijakan Penggunaan Jaring Trawl (Studi Kasus Penggunaan Jaring Trawl Oleh Nelayan Wilayah Perairan Gresik). JKMP Vol.4 No.1 Maret $2016: 1-18$

Genisa, (1998). Beberapa Catatan Tentang Alat Tangkap Ikan Pelagik Kecil. Oseana, Volume XXIII, Nomor 3 \& 4, 1998 :1934

Kusdiantoro, Fahrudin, A., Wisudo S.H., dan Juanda, B. (2019). Perikanan Tangkap di Indonesia: Potret dan Tantangan Keberlanjutannya. J. Sosek KP Vol. 14 No. 2 Desember 2019: 145-162

Mallawa, A., Amir F., Safruddin, Mallawa, E. (2020). Tingkat Keberlanjutan Alat Penangkapan Ikan Cakalang (Katsuwonus pelamis) Skala Tradisional Di Perairan Selat Makassar, Sulawesi Selatan. Prosiding Simposium Nasional VII Kelautan dan Perikanan Universitas Hasanuddin, 5 Juni 2020 : 217-226

Muhfizar dan Poltak, H. (2020). Manajemen Usaaha Perikanan. Ahlimedia Press, Malang. Hal 37

Pramudya, B. (2014). Ekonomi Teknik. IPB Press, Bogor. Hlm 100.

Pratama F.A., Boesono, H., Dwi H.T. (2012). Analisis Kelayakan Finansial Usaha Penangkapan Ikan Menggunakan Panah dan Bubu Dasar Di Perairan Karimunjawa. Journal of Fisheries Resources Utilization Management and Technology Vol.1 No.1, Hal 22-31

Silaban, J., Mustaruddin, Soeboer, D.A. (2017). Penentuan Alat Tangkap Unggulan Untuk Ikan Pelagis Kecil Di Pelabuhan Ratu Sukabumi. Albacore Vol.1 No.2 Juni 2017 : 225-234

Subani W dan Barus, H.R. (1989). Alat Penangkapan Ikan dan Udang Laut di Indonesia. Jurnal Penelitian Perikanan Laut. Jakarta. Balai
Penelitian Perikanan laut.

BadanPenelitian dan

Pengembangan Pertanian.

Departemen Pertanian. Hal 219220.

Tangke, U. (2011). Analisis Kelayakan Usaha Perikanan Tangkap Menggunakan Alat Tangkap Gill Net dan Purse Seine Di Kecamatan Leihitu Kabupaten Maluku Tengah Provinsi Maluku. Jurnal Ilmiah agribisnis dan Perikanan (agrikan UMMU-Ternate) Volume 4 Edisi 1 (Mei 2011)

Wiratama, Wijayanto, D., Jayanto, B.B. (2017). Analisis Kelayakan Usaha Penngkapan Ikan Pada Alat Tangkap Pole and Line Di Pelabuhan Perikanan Pantai (PPP) Labuhan Lombok. Jurnal Perikanan Tangkap Vol.1 No.3 https://ejournal2.undip.ac.id/index .php/juperta/article/view/1883

Wisudo, S.H., Sakai, H.., Takeda, S., Akiyama S., and Arimoto, T.. (2002). Total Lumen Estimation of Fishing Lamp by Means of Rousseau Diagram Analisys With Lux Measurement. Proceddings of International Commerative Simposium 70th Anniversary of the Javanesse Society of fisheries Science. Fisheries Science Tokyo. https://doi.org/10.2331/fishsci.68. sup1_479 
